\title{
A proposed asymmetrical configuration of cascaded multilevel inverter topology for high level generation
}

\author{
Lipika Nanda, Chitralekha Jena, Arjyadhara Pradhan, Babita Panda \\ Department of Electrical Engineering, School of Electrical Engineering, Kalinga Institute of Industrial Technology, Odisha, India
}

\begin{tabular}{|c|c|}
\hline Article Info & ABSTRACT \\
\hline Article history: & \multirow{7}{*}{$\begin{array}{l}\text { Multilevel inverters are having high demand in high power applications. It } \\
\text { works in medium voltage range. In this converter, for specific time intervals } \\
\text { fewer switches will be conducting so switching loss is also reduced. This } \\
\text { paper represents overall total harmonic distortion (THD) for different levels } \\
\text { and different carrier frequencies. Switching loss, conduction loss of inverter } \\
\text { has been discussed and hence inverter efficiency can be calculated. Phase } \\
\text { displacement pulse width modulation method has been proposed in order to } \\
\text { generate pulses. The proposed topology is well presented by its practical } \\
\text { implementation with two current direct sources. All the simulations are } \\
\text { being carried out using MATLAB/Simulink platform to validate the } \\
\text { hardware results. }\end{array}$} \\
\hline Received Jul 2, 2021 & \\
\hline Revised Jan 17, 2022 & \\
\hline Accepted Jan 25, 2022 & \\
\hline Keywords: & \\
\hline & \\
\hline $\begin{array}{l}\text { Bidirectional switch } \\
\text { Switching loss }\end{array}$ & \\
\hline
\end{tabular}

This is an open access article under the CC BY-SA license.

Symmetric MLI

Total harmonic distortion

Voltage stress

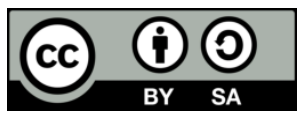

\section{Corresponding Author:}

Lipika Nanda

Department of Electrical Engineering, School of Electrical Engineering

Kalinga Institute of Industrial Technology

Odisha 751024, India

Email: lnandafel@kiit.ac.in

\section{INTRODUCTION}

Multilevel inverters are highly in demand in high power and medium voltage applications [1]. There are mainly three different types of multilevel inverters are being focused for industrial applications. Various topologies had been developed since 1970. It can be interfaced to renewable sources i.e., solar photo voltaic, wind and fuel gas [2]-[4]. Considering the number of components, high reliability cascaded multi level inverter (MLI) is being chosen. As the number of level increases, the number of H-bridges also increases [5], [6]. This makes the system more complicated. By increasing the number of levels in the inverter, the output voltages have more steps generating a staircase waveform, which has a reduced harmonic distortion. Depending upon the voltages sources cascaded MLI are classified into two, i.e. symmetrical and asymmetrical Cascaded MLI [7]. Direct voltages are having different values in asymmetrical Cascaded multilevel inverter [8]. So, the Inverter achieves higher number of voltage levels compared with symmetrical configuration for same number of level generation [9], [10]. Several newly developed MLI topologies, popularly known as "reduced device count (RDC)," have been reported in recent years [11]-[15]. In this paper a novel topology has been proposed and its asymmetrical configuration has been emphasized to produce more number of levels. As the number of levels increased the output waveforms become more sinusoidal in nature. Hence total harmonic distortion (THD) reduces. Phase-shifted and level-shifted are the two modulation schemes using carrier based pulse width modulation (PWM). Using the same frequency modulation index in the different modulation techniques, the equivalent switching frequency in the level shifted technique is significantly lower than in the phased shifted method [16]-[21]. This turns into a better 
harmonic performance. Hence level shifted PWM techniques are being used. The main features of the proposed topology is it has reduced number of dc sources and semiconductor switches also.

\section{RESEARCH METHODOLOGY}

\subsection{Existing topology}

The existing topology as shown in Figure 1 has two voltage sources $V_{1}$ and $V_{2}$. It has two capacitors $\mathrm{C}_{1}$ and $\mathrm{C}_{2}$ connected to one voltage source side i.e., $\mathrm{V}_{1}$ and seven switches. If the values of $\mathrm{V}_{1}$ and $\mathrm{V}_{2}$ are equal it is treated asymmetrical configuration. It can produce up to 11 levels with certain voltage combination. Hence to generate higher levels a new modified topology has been proposed in Figure 2.

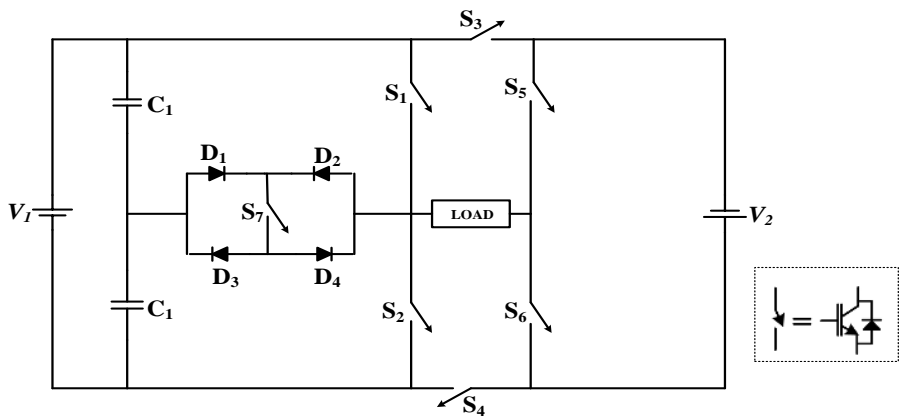

Figure 1. Existing topology

\subsection{Proposed topology}

The existing topology has been modified and represented in Figure 2 in order to generate higher levels. As the proposed topology also generates same levels of output voltage and current waveforms in symmetrical configuration of existing topology, its asymmetrical configuration has been highlighted and presented in this section. It has two voltage sources i.e. $\mathrm{V}_{1}$ and $\mathrm{V}_{2}$ and four capacitors i.e. $\mathrm{C}_{1}-\mathrm{C}_{4}$ connected as shown in Figure 2. It has six unit directional i.e., $S_{1}, S_{2}, S_{3}, S_{4}, S_{7}$, and $S_{8}$ and two bidirectional switches i.e., $\mathrm{S}_{5}$ and $\mathrm{S}_{8}$ in the circuit.

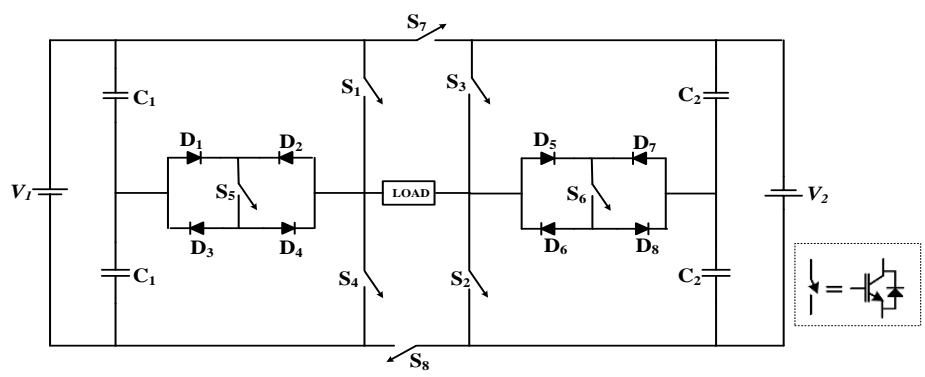

Figure 2. Modified topology

\section{MODES OF OPERATION}

In this section different modes of operation of the proposed converter for thirteen level generation have been represented from mode 1 to mode 13 order to generate first level i.e., $V_{d c}, S_{5}, S_{2}$ and $\mathrm{S}_{8}$ are conducting. Similarly, to generate second level, in mode 2 operation, $\mathrm{S}_{6}, \mathrm{~S}_{4}$, and $\mathrm{S}_{8}$ are turned on keeping capacitor $\mathrm{C}_{2}$ charged. In mode 3 operation, $\mathrm{C}_{2}$ discharged by charging capacitor $\mathrm{C}_{1}$.In order to generate all the six positive levels, the lower switch i.e., $\mathrm{S}_{8}$ is being turned on and to generate all the six negative levels, switch $S 7$ has been turned on in the Figure 2. Similarly, $S_{1}, S_{7}, S_{3}$, or $S_{2}, S_{4}$, and $S_{8}$ are turned $\mathrm{ON}$, short circuiting the load, to generate zero level respectively. 


\section{SWICHING STATES}

This section represents various switching states of the proposed topology. It shows $V_{1}=V / 2$, $\mathrm{V}_{2}=\mathrm{V}$ where $\mathrm{V}_{\mathrm{dc}}=\mathrm{V} / 4$ which is known as unsymmetrical binary configuration, to generate 13 level sand $\mathrm{V}_{1}=\mathrm{V}$, $\mathrm{V}_{2}=3 \mathrm{~V}$ where $\mathrm{V}_{\mathrm{dc}}=\mathrm{V} / 2$, which is called as unsymmetrical trinary configuration, to generate 17 levels respectively. Figure 3 depicts to generate first level i.e., $\mathrm{V}_{\mathrm{dc}}$ in thirteen level generations $\mathrm{Switches}_{5}, \mathrm{~S}_{2}, \mathrm{~S}_{8}$ are conducting. To generate second level i.e., $2 \mathrm{~V}_{\mathrm{dc}}$ in thirteen level generations switches $\mathrm{S}_{6}, \mathrm{~S}_{4}, \mathrm{~S}_{8}$ are conducting. Similarly, six positive levels are generated and six negative levels are generated along with zero level as represented in different modes of operation in Figure 3 (see Appendix). Table 1 explains the different switching strategies of the proposed converter. It also depicts about the switches and diodes are conducting for particular level generation.

Table 1. Different switching strategies

\begin{tabular}{|c|c|c|c|c|c|}
\hline \multicolumn{3}{|c|}{13 Levels } & \multicolumn{3}{|c|}{17 Levels } \\
\hline Output & Conducting switches & Conducting Diodes & Output & Conducting switches & Conducting Diodes \\
\hline $\mathrm{V}_{\mathrm{dc}}$ & $\mathrm{S}_{5}, \mathrm{~S}_{2}, \mathrm{~S}_{8}$ & $\mathrm{D} 1, \mathrm{D} 4$ & $\overline{V_{\mathrm{dc}}}$ & $\mathrm{S}_{5}, \mathrm{~S}_{2}, \mathrm{~S}_{8}$ & $\mathrm{D} 1, \mathrm{D} 4$ \\
\hline $2 \mathrm{~V}_{\mathrm{dc}}$ & $\mathrm{S}_{6}, \mathrm{~S}_{4}, \mathrm{~S}_{8}$ & D5, D6 & $2 V_{\mathrm{dc}}$ & $\mathrm{S}_{1}, \mathrm{~S}_{2}, \mathrm{~S}_{8}$ & NIL \\
\hline $3 \mathrm{~V}_{\mathrm{dc}}$ & $\mathrm{S}_{5}, \mathrm{~S}_{6}, \mathrm{~S}_{8}$ & D1, D4, D5, D8 & $3 \mathrm{~V}_{\mathrm{dc}}$ & $\mathrm{S}_{8}, \mathrm{~S}_{4}, \mathrm{~S}_{6}$ & D5, D8 \\
\hline $4 V_{\mathrm{dc}}$ & $\mathrm{S}_{8}, \mathrm{~S}_{4}, \mathrm{~S}_{3}$ & NIL & $4 V_{\mathrm{dc}}$ & $\mathrm{S}_{8}, \mathrm{~S}_{5}, \mathrm{~S}_{6}$ & $\mathrm{D} 1, \mathrm{D} 2, \mathrm{D} 3, \mathrm{D} 4$ \\
\hline $5 \mathrm{~V}_{\mathrm{dc}}$ & $\mathrm{S}_{8}, \mathrm{~S}_{5}, \mathrm{~S}_{3}$ & D1, D4 & $5 \mathrm{~V}_{\mathrm{dc}}$ & $\mathrm{S}_{1}, \mathrm{~S}_{6}, \mathrm{~S}_{8}$ & D5, D8 \\
\hline $6 \mathrm{~V}_{\mathrm{dc}}$ & $\mathrm{S}_{8}, \mathrm{~S}_{1}, \mathrm{~S}_{3}$ & NIL & $6 \mathrm{~V}_{\mathrm{dc}}$ & $\mathrm{S}_{8}, \mathrm{~S}_{4}, \mathrm{~S}_{3}$ & NIL \\
\hline 0 & $\mathrm{~S}_{1}, \mathrm{~S}_{3}, \mathrm{~S}_{7}$ & NIL & $7 V_{\mathrm{dc}}$ & $\mathrm{S}_{8}, \mathrm{~S}_{5}, \mathrm{~S}_{3}$ & D1, D4 \\
\hline$-\mathrm{V}_{\mathrm{dc}}$ & $\mathrm{S}_{5}, \mathrm{~S}_{3}, \mathrm{~S}_{7}$ & D2, D3 & $8 V_{\mathrm{dc}}$ & $\mathrm{S}_{8}, \mathrm{~S}_{1}, \mathrm{~S}_{3}$ & NIL \\
\hline$-2 V_{d c}$ & $\mathrm{~S}_{7}, \mathrm{~S}_{1}, \mathrm{~S}_{6}$ & D7, D6 & 0 & $\mathrm{~S}_{1}, \mathrm{~S}_{2}, \mathrm{~S}_{3}$ & NIL \\
\hline$-3 V_{d c}$ & $\mathrm{~S}_{5}, \mathrm{~S}_{6}, \mathrm{~S}_{7}$ & D7, D6, D2, D3 & $-\mathrm{V}_{\mathrm{dc}}$ & $\mathrm{S}_{7}, \mathrm{~S}_{3}, \mathrm{~S}_{5}$ & D2, D3 \\
\hline$-4 V_{d c}$ & $\mathrm{~S}_{2}, \mathrm{~S}_{1}, \mathrm{~S}_{7}$ & NIL & $-2 V_{d c}$ & $\mathrm{~S}_{7}, \mathrm{~S}_{3}, \mathrm{~S}_{4}$ & NIL \\
\hline$-5 \mathrm{~V}_{\mathrm{dc}}$ & $\mathrm{S}_{2}, \mathrm{~S}_{5}, \mathrm{~S}_{7}$ & D2, D3 & $-3 V_{d c}$ & $\mathrm{~S}_{6}, \mathrm{~S}_{1}, \mathrm{~S}_{7}$ & D7, D6 \\
\hline$-6 \mathrm{~V}_{\mathrm{dc}}$ & $\mathrm{S}_{2}, \mathrm{~S}_{4}, \mathrm{~S}_{7}$ & NIL & $-4 V_{d c}$ & $\mathrm{~S}_{6}, \mathrm{~S}_{5}, \mathrm{~S}_{7}$ & D2, D3, D7, D6 \\
\hline $\mathrm{x}$ & $\mathrm{x}$ & $\mathrm{x}$ & $-5 \mathrm{~V}_{\mathrm{dc}}$ & $\mathrm{S}_{7}, \mathrm{~S}_{6}, \mathrm{~S}_{4}$ & D7, D6 \\
\hline $\mathrm{x}$ & $\mathrm{x}$ & $\mathrm{x}$ & $-6 V_{d c}$ & $\mathrm{~S}_{2}, \mathrm{~S}_{1}, \mathrm{~S}_{7}$ & NIL \\
\hline $\mathrm{x}$ & $\mathrm{x}$ & $\mathrm{x}$ & $-7 V_{d c}$ & $\mathrm{~S}_{2}, \mathrm{~S}_{7}, \mathrm{~S}_{5}$ & D2, D3 \\
\hline $\mathrm{X}$ & $\mathrm{x}$ & $\mathrm{x}$ & $-8 V_{d c}$ & $\mathrm{~S}_{2}, \mathrm{~S}_{4}, \mathrm{~S}_{7}$ & NIL \\
\hline
\end{tabular}

\section{SIMULATION RESULT ANALYSIS}

Various types of the pulse width modulation (PWM) techniques are existing out of which level shifted PWM technique is being considered because of its many advantages over other conventional techniques. Figure 4 depicts the simulation diagram of the proposed converter at carrier frequency $10 \mathrm{KHz}$ and modulation index at $1 . S_{5}$ and $S_{6}$ are two bidirectional switches and $S_{1}, S_{2}, S_{3}, S_{4}, S_{7}, S_{8}$ are unidirectional switches in Figure 2. Figure 4 represents load voltage and load current wave form at carrier frequency $=10$ $\mathrm{KHz}$. Simulation has been carried out for $\mathrm{R}=10 \Omega, \mathrm{L}=25 \mathrm{mH}$ at modulation index 1 .

Figure 4 (a) indicates output load voltage for 13 level. Average output voltage is $43.85 \mathrm{~V}$ at $\mathrm{THD}=5.44 \%$. The fundamental cycle has been represented in voltage waveform which is from 0 to 0.02 sec. Voltage THD also within IEEE standard. Six positive levels, six negative levels of unequal voltage distribution represented in Figure 4 (a) which shows the asymmetric nature of the proposed multilevel inverter. Figure 4 (b) indicates output load current for 13 level. Average output load current is $3.45 \mathrm{~A}$ at THD $=0.28 \%$. Current THD is also within IEEE standard.

Fundamental cycle has been represented in voltage waveform which is from 0 to $0.02 \mathrm{sec}$. Figure 4 (c) indicates average output voltage is $38.85 \mathrm{~V}$ with THD $=3.9 \%$. Figure 4 (d) indicates average output current is $3.5 \mathrm{~A}$ with $\mathrm{THD}=1.7 \%$. Voltage THD also within IEEE standard. Eight positive levels, eight negative levels of unequal voltage distribution along with zero level represented in Figure 4 (c) which shows the asymmetric nature of the proposed multilevel inverter. Figure 4 (d) indicates output load current for 17 level. Average output load current is $3.5 \mathrm{~A}$ at THD $=1.7 \%$. Current THD is also within IEEE standard. Figures 4 (a) and 4 (b) also depict with increase in level generation of the same converter THD is reduced.

Table 2 depicts various losses occurred across the semiconductor switches i.e., at $10 \mathrm{KHz}$ carrier frequency. Table 2 also describes that conduction loss across the switches is same where, as switching loss depends on the usability of the switch. Switches $S_{7}$ and $S_{8}$ are mostly used when the converter is working to generate positive levels and negative levels respectively. Hence switching losses are more in $S_{7}$ and $S_{8}$ compared to other switches.

Table 3 depicts about the inverter loss. According to the various researchers [22]-[25] an inverter has major two types of losses i.e., switching loss which occurs when a switch is conducted (turn on) and also when it is in off state (turn off), conduction loss when the switch is in conduction state. It has been calculated from its input power and output power with its voltage THDs and current THDs. Table 3 depicts with increase in 
carrier frequency voltage THD enhanced and current THD decreased. At $10 \mathrm{KHz}$ carrier frequency voltage THD and current THD are found to be minimum. Hence it is the optimum condition of the converter which can be considered for hardware realization.

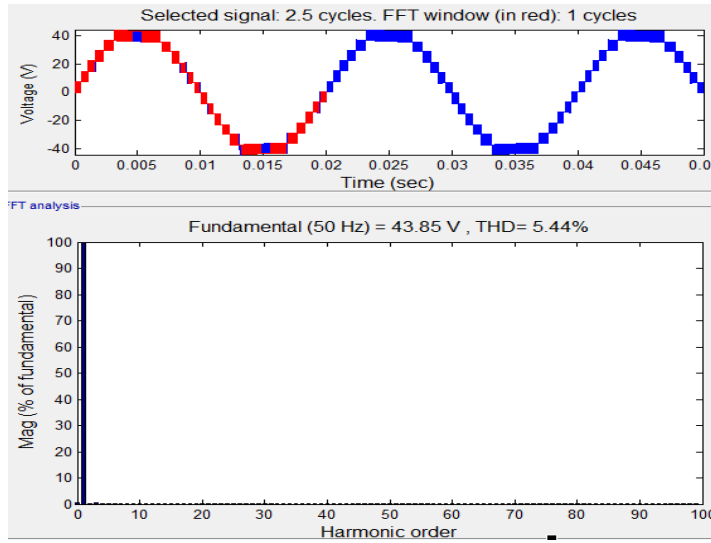

(a)

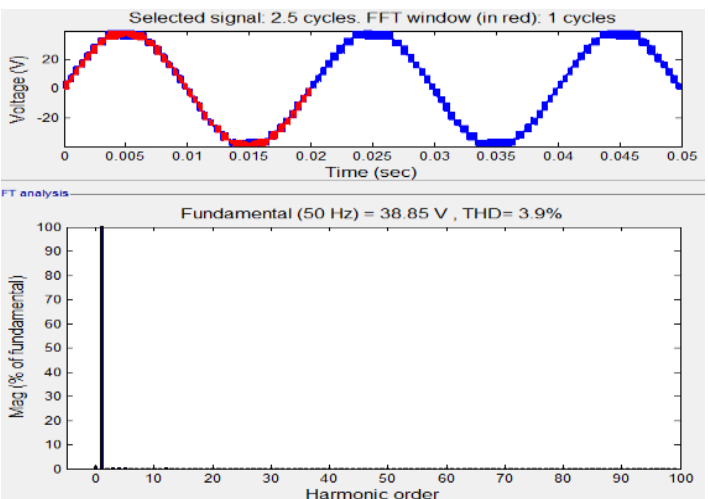

(c)
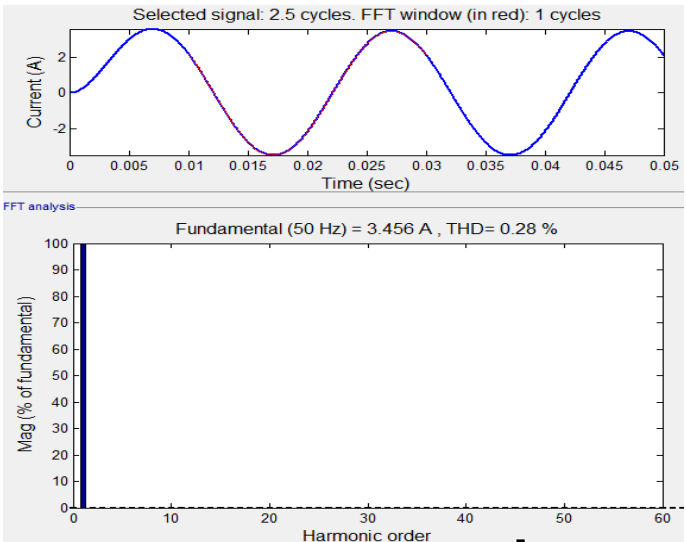

(b)
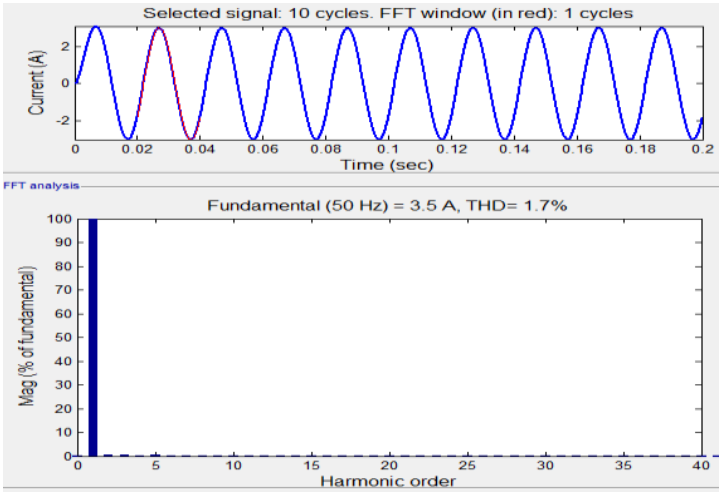

(d)

Figure 4. Simulation results of voltage across load and current for (a) asymmetrical output voltage signals, (b) asymmetrical output current signal, (c) asymmetrical output voltage signal, and (d) asymmetrical output current (17 level)

Table 2. Loss calculation at $10 \mathrm{KHz}$ carrier frequency

\begin{tabular}{lccccccc}
\hline & $\mathrm{S}_{1}$ & \multicolumn{1}{c}{$\mathrm{S}_{2}$} & \multicolumn{1}{c}{$\mathrm{S}_{3}$} & \multicolumn{1}{c}{$\mathrm{S}_{4}$} & \multicolumn{1}{c}{$\mathrm{S}_{5}$} & \multicolumn{1}{c}{$\mathrm{S}_{6} \mathrm{~S}_{7}$} & $\mathrm{~S}_{8}$ Tota \\
\hline Switching loss (in W) & 0.035 & 0.0016 & 0.0012 & 0.0023 & 0.05 & 0.04890 .06 & 0.060 .259 \\
Conduction Loss (in W) & 0.0051 & 0.0052 & 0.005 & 0.0052 & 0.0055 & 0.00510 .005 & 0.0450 .081 \\
Total Loss (in W) & 0.0401 & 0.0068 & 0.0062 & 0.0075 & 0.0555 & 0.0540 .065 & 0.1050 .0249 \\
\hline
\end{tabular}

Table 3. Inverter loss and THD across the RL-load

\begin{tabular}{ccccrr}
\hline Carrier Frequencies (in KHz) & Input power (in W) & Output power (in W) & Inverter (in W) & VTHD & ITHD \\
\hline 1 & 62.26 & 56.7 & 8.56 & 6.36 & 1.91 \\
3 & 65.9 & 57.20 & 8.7 & 6.72 & 1.45 \\
5 & 66.83 & 57.6 & 9.23 & 6.89 & 1.05 \\
7 & 68.11 & 58.6 & 9.51 & 6.98 & 0.74 \\
10 & 69.49 & 59.22 & 10.27 & 5.44 & 0.28 \\
\hline
\end{tabular}

Table 4 depicts voltage THD is reduced and current THD is increased with increase in modulation index. Hence it is always advised to operate the converter at high carrier frequency and at modulation index 1. At $10 \mathrm{KHz}$ carrier frequency voltage THD and current THD are found to be minimum at modulation index 1. Figure 5 represents current THD at various carrier frequencies of the inverter. Current THD has been reduced as the carrier frequency increases. It indicates that current becomes more sinusoidal at higher carrier 
frequencies. With high modulation index voltage THD reduces which has been observed in Figure 6 . Hence it was advised to operate the inverter at modulation index 1 in order to make the inverter output more distortion free. Also, in Table 4 it was mentioned clearly.

Table 4. Modulation index verses THD of proposed topology (13 level)

\begin{tabular}{|c|c|c|}
\hline \multicolumn{3}{|c|}{ Modulation Index VTHD ITHD } \\
\hline 0.6 & 12.2 & 0.12 \\
\hline 0.7 & 11.8 & 0.18 \\
\hline 0.8 & 10.42 & 0.22 \\
\hline 0.9 & 7.72 & 0.25 \\
\hline 1 & 5.44 & 0.28 \\
\hline
\end{tabular}

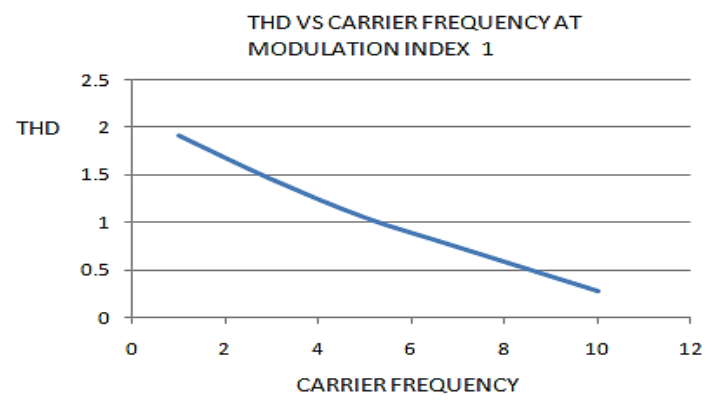

Figure 5. Current THD vs carrier frequency

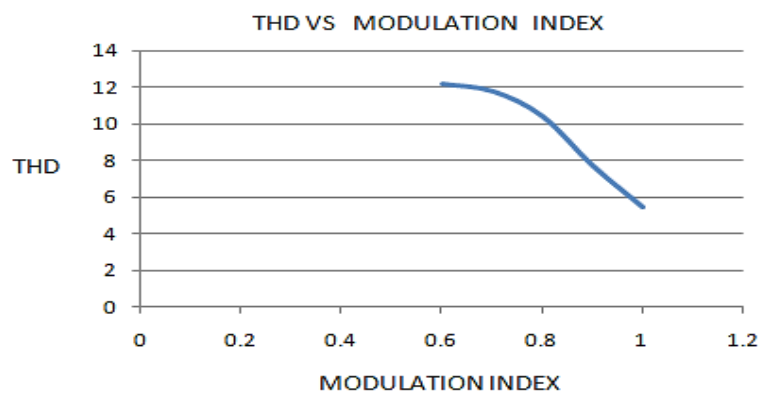

Figure 6. Voltage THD vs modulation index at $10 \mathrm{KHz}$

\section{HARDWARE REALIZATION}

To verify the effectiveness of the proposed topology, experimental results have been presented in this section. In Figure 7 the entire converter has been considered as a system/Plant to which two sources are attached. The output of the inverter is PWM controlled and it is controlling the system operation. The block diagram of hardware which has been designed in research lab-III of Kalinga Institute of Industrial Technology deemed to be university (KIIT). Circuit is designed using EAGLE software. They are fed to gate driver circuits. Gate driver circuits have input supply from 230/15 V, 1A step down transformer. Pulses generated from driver circuits have been fed to each MOSFET IRF540 N gate terminals. Output of the power circuit is given to the load RL type RO2. Power supply of MOSFET gate driver circuit 3. Gate drive circuit 4. Main power circuit 5. Output connector from DSPACE. Figure 8 explains the hardware diagram of the proposed converter where input power supplies are through MOSFET gate driver circuits. MOSFET IRF540 Ns are taken as switches. Six MOSFETS work with six gate driver circuits. DSPACE has been connected to output waveforms in order to describe the turn off and on state of the inverter.

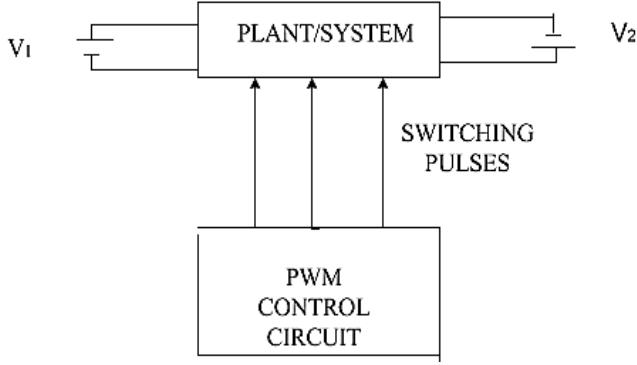

Figure 7. Overall scheme of the system

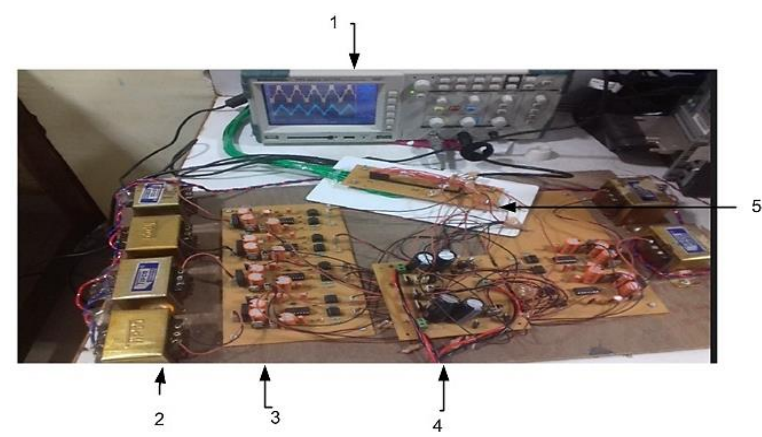

Figure 8. Overall hardware design of the proposed topology

Figures 9 (a) and 9 (b) depict the two input signals of the inverter. V1 is $10 \mathrm{~V}$ and V2 is $5 \mathrm{~V}$. It shows the asymmetrical configuration of the proposed inverter. Figure 9(c) represents the output signals. It shows output voltage as $14 \mathrm{~V}$ and current as 0.125 A respectively with $\mathrm{R}=120 \Omega, \mathrm{L}=50 \mathrm{mH}$ at carrier frequency $1 \mathrm{KHz}$ and input capacitors of $470 \mu \mathrm{F}$ each. 


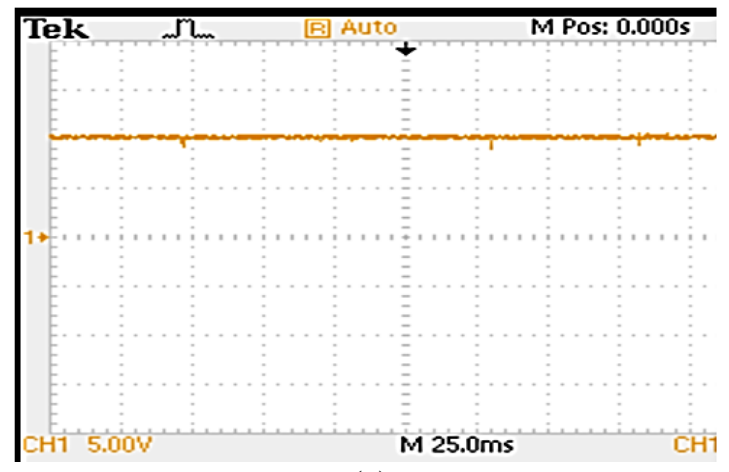

(a)

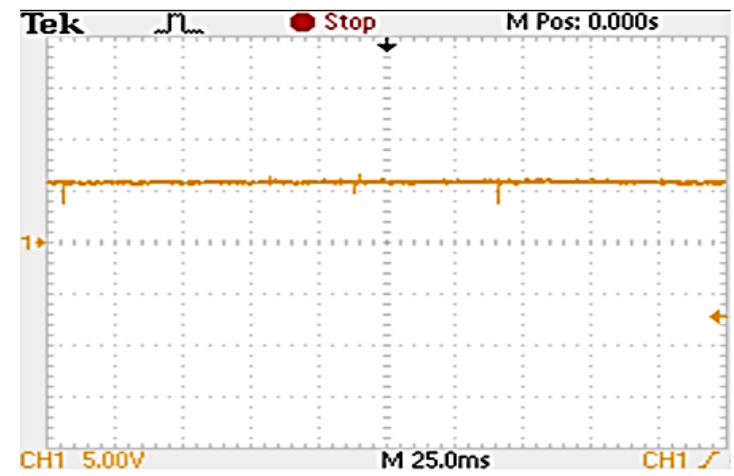

(b)

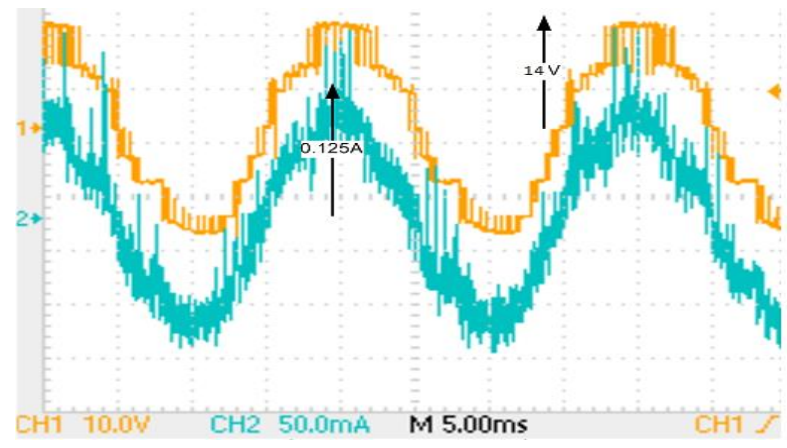

(c)

Figure 9. Hardware results for (a) input voltage V1=10 V, (b) input voltage V2=5V, and (c) peak voltage and current across RL-load

\section{CONCLUSION}

In this research article, the detailed analysis of the proposed asymmetrical cascaded multi level inverter has been carried out successfully at different modulation index and carrier frequencies. The output waveforms are more sinusoidal and hence better power quality can be obtained at higher carrier frequencies. The proposed topology has been fabricated and verified with its simulation result also. Input voltage of $15 \mathrm{~V}$ and output voltage is $14 \mathrm{~V}$ which is quite high compared to other existe topologies as cited in the references. Also THDs if the proposed topology are nominal.

\section{REFERENCES}

[1] X. Li, Z. Deng, Z. Chen, and Q. Fei, “Analysis and Simplification of Three-Dimensional Space Vector PWM for Three-Phase Four-Leg Inverters," in IEEE Transactions on Industrial Electronics, vol. 58, no. 2, pp. 450-464, Feb. 2011, doi: 10.1109/TIE.2010.2046610.

[2] J. Rodriguez, J.-Sheng Lai, and F. Z. Peng, "Multilevel inverters: a survey of topologies, controls, and applications," in IEEE Transactions on Industrial Electronics, vol. 49, no. 4, pp. 724-738, Aug. 2002, doi: 10.1109/TIE.2002.801052.

[3] L. Nanda, A. Dasgupta, and U. K. Rout, "A Comparative Studies of Cascaded Multilevel Inverters Having Reduced Number of Switches with R and RL-Load," International Journal of Power Electronics and Drive Systems (IJPEDS), vol. 8, no. 1, pp. 4050, 2017, doi: 10.11591/ijpeds.v8.i1.pp40-50.

[4] S. De, D. Banerjee, K. S. Kumar, K. Gopakumar, R. Ramchand, and C. Patel, "Multilevel inverters for low-power application," IET Power Electronics, vol. 4, no. 4, pp. 384-392, 2011, doi: 10.1049/iet-pel.2010.0027.

[5] G. Grandi, C. Rossi, D. Ostojic, and D. Casadei, "A New Multilevel Conversion Structure for Grid-Connected PV Applications," in IEEE Transactions on Industrial Electronics, vol. 56, no. 11, pp. 4416-4426, Nov. 2009, doi: 10.1109/TIE.2009.2029587.

[6] S. Gautam, S. Gupta, and L. Kumar, "Hybrid topology of symmetrical multi level inverter using less number of devices," IET Power Electronics, vol. 8, no. 11, pp. 2125-2135, 2015, doi: 10.1049/iet-pel.2015.0037.

[7] E. Najafi and A. H. M. Yatim, "Design and Implementation of a New Multilevel Inverter Topology," in IEEE Transactions on Industrial Electronics, vol. 59, no. 11, pp. 4148-4154, Nov. 2012, doi: 10.1109/TIE.2011.2176691.

[8] M. G. Prakash, M. Balamurugan, and S. Umashankar, "A new multi level inverter with reduced number of switches," International Journal of Power Electronics and Drive System (IJPEDS), vol. 5, no. 1, p. 63-70, 2014.

[9] E. Babaei, "A Cascade Multilevel Converter Topology With Reduced Number of Switches," in IEEE Transactions on Power Electronics, vol. 23, no. 6, pp. 2657-2664, Nov. 2008, doi: 10.1109/TPEL.2008.2005192.

[10] L. Nanda, P. Bharti, and A. Dasgupta, "Symmetrical And Asymmetrical Topology of Cascaded Multilevel Inverter With Reduced Number of Switches And DC Sources," 2019 IEEE International Conference on Sustainable Energy Technologies and Systems (ICSETS), 2019, pp. 230-235, doi: 10.1109/ICSETS.2019.8744931. 
[11] L. Nanda, A. Dasgupta, and U. K. Rout, “A comparative Analysis of Symmetrical and Asymmetrical Cascaded Multilevel Inverter Having Reduced Number of Switches and DC Sources," International Journal of Power Electronics and Drive Systems, vol 8, no. 4, pp. 1595-1602, 2017, doi: 10.11591/ijpeds.v8.i4.pp1595-1602.

[12] E. Babaei, S. H. Hosseini, G. B. Gharehpetian, M. T. Haque, and M. Sabahi, "Reduction of dc voltage sources and switches in asymmetrical multilevel converters using a novel topology," Electric Power Systems Research, vol. 77, no. 8, pp. 1073-1085, 2007, doi: 10.1016/j.epsr.2006.09.012.

[13] M. Veenstra and A. Rufer, "Control of a hybrid asymmetric multilevel inverter for competitive medium-voltage industrial drives," IEEE Trans. Ind. Appl., vol. 41, no. 2, pp. 655-664, 2005, doi: https://doi.org/10.1109/TIA.2005.844382.

[14] L. Nanda, S. Mohapatra, A. Pradhan, and S. R. Prusty, "Hybridized Symmetrical Multilevel Inverter Topology with reduced number of Switches and DC Sources," 2021 International Conference on Artificial Intelligence and Smart Systems (ICAIS), 2021, pp. 1499-1503, doi: 10.1109/ICAIS50930.2021.9395940.

[15] R. S. Alishah, D. Nazarpour, S. H. Hosseini, and M. Sabahi, "Novel Topologies for Symmetric, Asymmetric, and Cascade Switched-Diode Multilevel Converter with Minimum Number of Power Electronic Components," in IEEE Transactions on Industrial Electronics, vol. 61, no. 10, pp. 5300-5310, Oct. 2014, doi: 10.1109/TIE.2013.2297300.

[16] J. Ebrahimi, E. Babaei, and G. B. Gharehpetian, "A New Multilevel Converter Topology With Reduced Number of Power Electronic Components," in IEEE Transactions on Industrial Electronics, vol. 59, no. 2, pp. 655-667, Feb. 2012, doi: 10.1109/TIE.2011.2151813.

[17] L. Nanda, A. Dasgupta, and U. K. Rout, "A Comparative Studies of Cascaded Multilevel Inverters Having Reduced Number of Switches with R and RL-Load," International Journal of Power Electronics and Drive System (IJPEDS), vol. 8, no. 1, pp. 40-50, 2017, doi: 10.11591/ijpeds.v8.i1.pp40-50.

[18] A. Mokhberdoran and A. Ajami, "Symmetric and Asymmetric Design and Implementation of New Cascaded Multilevel Inverter Topology," in IEEE Transactions on Power Electronics, vol. 29, no. 12, pp. 6712-6724, Dec. 2014, doi: 10.1109/TPEL.2014.2302873.

[19] N. Farokhnia, S. H. Fathi, N. Yousefpoor, and M. K. Bakhshizadeh, "Minimizations of total harmonic distortion in a cascaded multilevel inverter by regulating of voltages DC sources," IET Power Electronics, vol. 5, no. 1, pp. 106-114, 2012, doi: 10.1049/iet-pel.2011.0092.

[20] S. Laali, K. Abbaszadeh, and H. Lesani, "Control of asymmetric cascaded multilevel inverters based on charge balance control methods," International Review of Electrical Engineering (IREE), vol. 6, no. 2, pp. 522-528, 2011.

[21] R. Shalchi, M. Alishah, D. Nazarpour, S. H. Hosseini, and M. Sabahi, "Novel topologies for symmetric, asymmetric, and cascade switched-diode multilevel converter with minimum number of power electronic components," IEEE Trans. Ind. Electron., vol. 61, no. 10, pp. 5300-5310, 2014, doi: 10.1109/TIE.2013.2297300.

[22] E. Babaei, S. Laali, and Z. Bayat, "A single phase cascaded multilevel inverter based on a new basic unit with reduced number of power switches," IEEE Transactions on Industrial Electronics, vol. 62, no. 2, Feb. 2015, doi: 10.1109/TIE.2014.2336601.

[23] R. Naderi and E. Babaei, “A New Multilevel Inverter: An Attempt to Reduce Power Components," 2021 12th Power Electronics, Drive Systems, and Technologies Conference (PEDSTC), 2021, pp. 1-6, doi: 10.1109/PEDSTC52094.2021.9405868

[24] U. Drofenik, and J.W. Kolar, "A general scheme for calculating switching- and conduction losses of power semiconductors in numerical circuit simulations of power electronic system," in Proc. of the $5^{\text {th }}$ Int. Power Electron. Conference, Niigata, Japan, 2005.

[25] K. K. Gupta, and S. Jain, "Comprehensive review of a recently proposed multilevel inverter," IET Power Electron., 2014, vol. 7, no. 3, pp. 467-479, doi: 10.1049/iet-pel.2012.0438.

\section{APPENDIX}
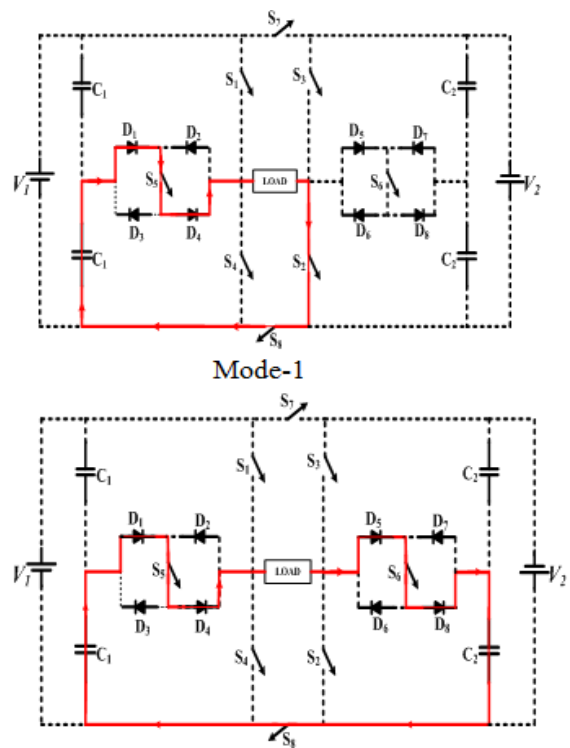

Mode-3

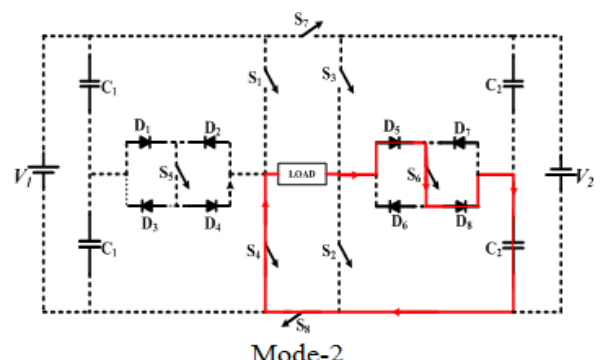

Mode-2

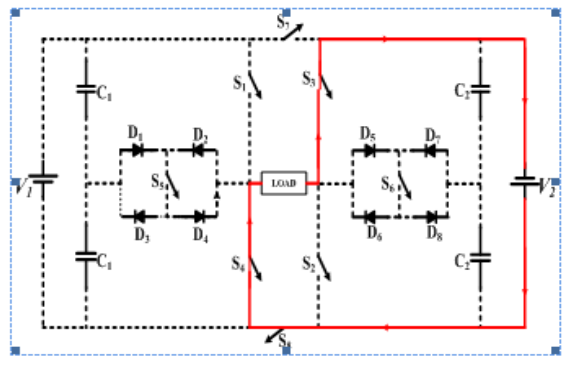

Mode-4

Figure 3. Modes of operation 

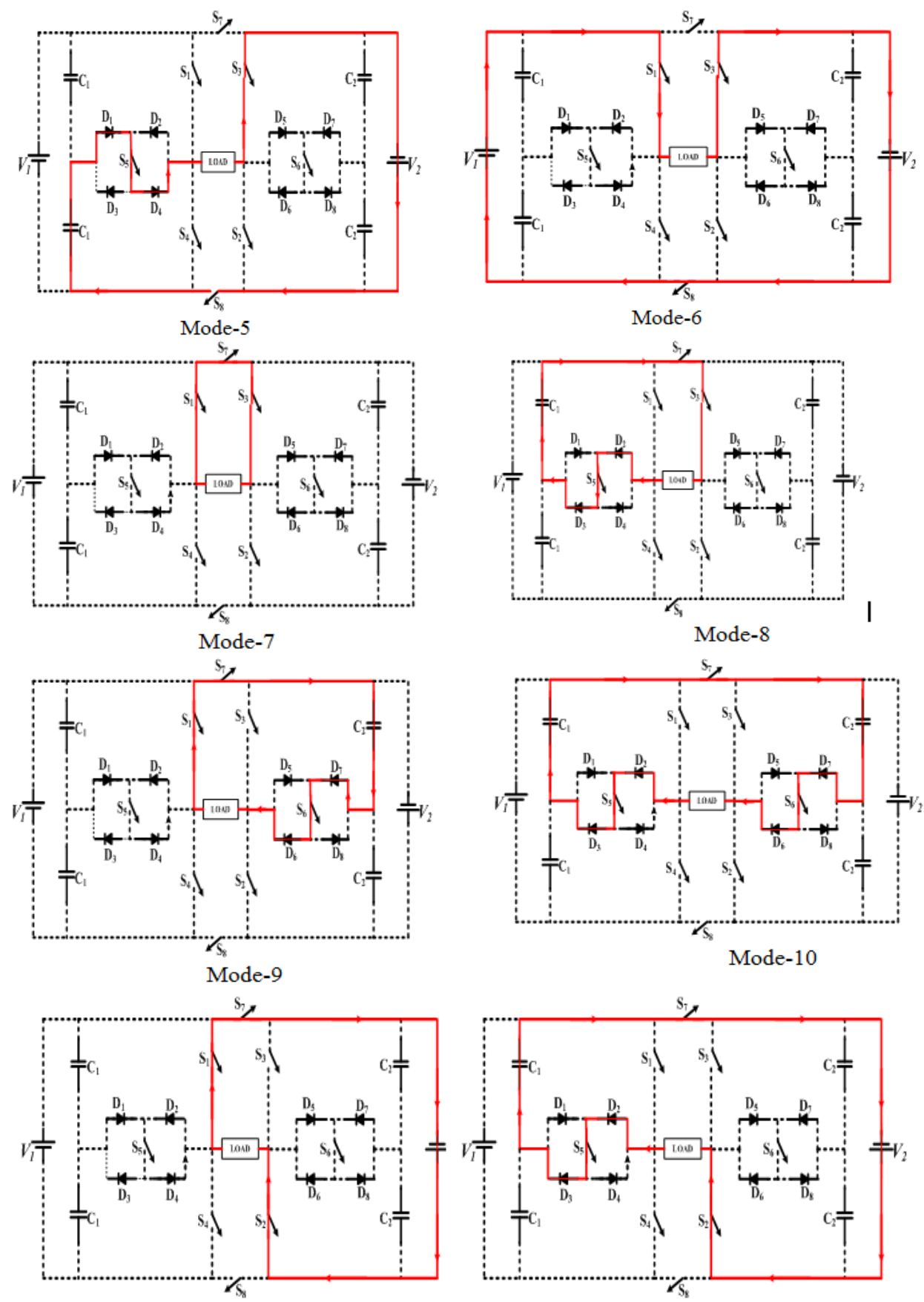

Mode-11

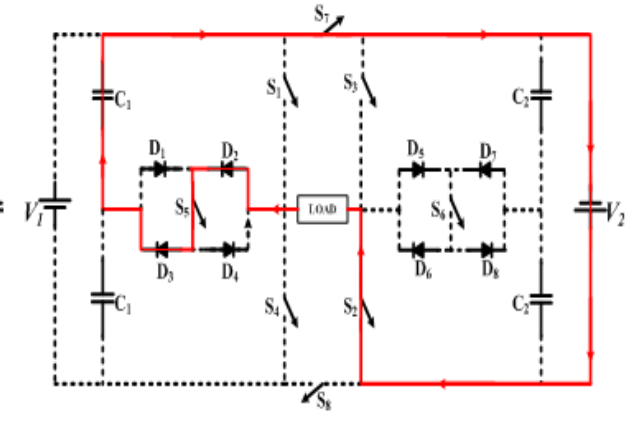

Mode-12

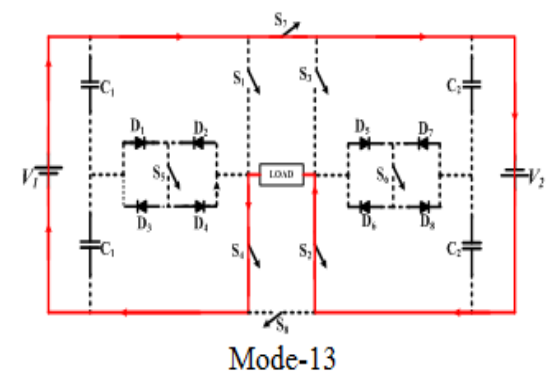

Figure 3. Modes of operation (continue) 


\section{BIOGRAPHIES OF AUTHORS}

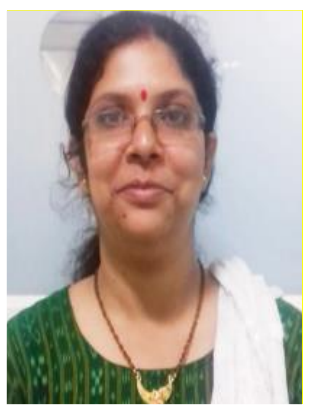

Lipika Nanda (D) ST SC is working as an assistant professor since 2007 in KIIT University.Her broad working area is design of power converters, multi-level inverter and its applications. She is a life member of various professional societies like SESI, ISTE, ISLE, ISCA, and IEEE. She has 3 Australian patents, 2 book chapters. She has published around 20 papers in international journals and conferences. She can be contacted at email: lnandafel@kiit.ac.in.

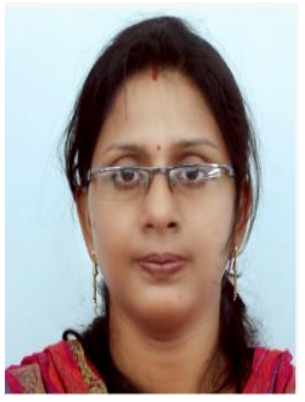

Chitralekha Jena (D) S. SC P had joined in KIIT University as an assistant professor since 2012.She had completed her PhD from Jadavpur University in the year of 2017. Her research area includes optimization of different power system problems, load frequency control, renewable energy, and power management of micro grid. She has more than 20 publications in reputed journals and conferences. She can be contacted at email: Chitralekha.jenafel@kiit.ac.in.

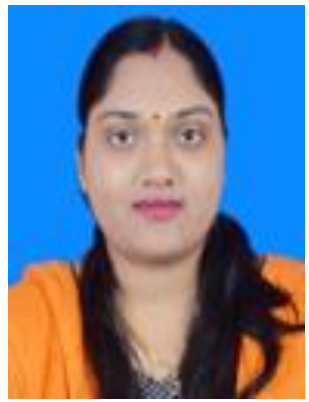

Arjyadhara Pradhan (D) SC SC is working as an assistant professor since 2009 in KIIT University. Her area of interest is Power Electronics, Electrical Drives, and Renewable Energy Systems. She has 8 Australian patents and 2 Indian patents. She has published around 20 papers in international journals and conferences. She can be contacted at email: arjyadhara.pradhanfel@kiit.ac.in.

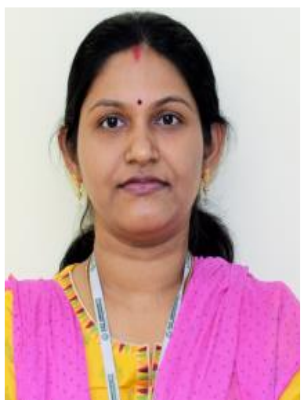

Babita Panda (iD 8. SC P has fifteen years of experience in education. She is working as an assistant professor in KIIT University. Her area of interest is Power Electronics, Electrical Drives, Renewable Energy Systems and Control System. She has more than 25 publications in reputed journals and conferences. She can be contacted at email: babitapfel@kiit.ac.in. 